\title{
Analisis Pelaksanaan Sistem Rujukan Berjenjang Bagi Peserta JKN di Puskesmas X Kota Surabaya
}

\author{
Analysis of The Implementation of Tiered Referral System for Participant of National \\ Health Security at Primary Health Center $X$ of Surabaya
}

Dwi Ratnasari

Perhimpunan Sarjana Kesehatan Masyarakat Indonesia (Persakmi) Kota Surabaya

Email: dwi.ratnasari-13@fkm.unair.ac.id

\begin{abstract}
The era of National Health Security (NHS) enacted tiered referral system start in primary health care. High number of referrals at Public Health Center (PHC) $X$ indicates that the implementation of referral system did not go well. The objectives of this study is to confirm implementation of refferal system in PHC in the era NHS based on the regulations and policies. This was descriptive observational research and cross sectional design with implementation research method. This research used triangulation to get deep information toward referral documents include referral data, registration book, medical records, referral letter, interview with refferal officer, and observation without intervention. This research was conducted at PHC X Surabaya on the Februari-March 2017. The results showed implementation of refferal system has appropriate with the regulations and the guidelines. The implementation has appropriate with 7 section on The Regulation of Health Minister No.1 of 2012. The implementation has appropriate with Guidelines of National Health Refferal include requirement to refer patient, refferal clinical procedure, and refferal administrative procedure, however there is not appropriate implementation: informed consent, contact to refferal destination healthcare, and print out of refferal paper. Recommendation for PHC is to do informed consent and print refferal letters 2 copies.
\end{abstract}

Keywords: national health security, public health center, refferal system

\section{ABSTRAK}

Era Jaminan Kesehatan Nasional memberlakukan sistem rujukan berjenjang yang dimulai dari FKTP. Tingginya angka rujukan di puskesmas $X$ mengindikasikan bahwa implementasi sistem rujukan belum berjalan dengan baik. Tujuan penelitian untuk melihat kesesuaian pelaksanaan sistem rujukan pada era JKN di puskesmas berdasarkan peraturan perundang-undangan dan kebijakan yang ada. Penelitian ini merupakan penelitian deskriptif observasional, dan rancang bangun cross sectional dengan metode riset implementasi. Penelitian ini melakukan triangulasi untuk mendapatkan informasi mendalam terhadap dokumen rujukan meliputi data rujukan, buku registrasi, rekam medis, dan surat rujukan, wawancara dengan petugas rujukan, serta observasi tanpa memberikan intervensi. Penelitian ini dilakukan di Puskesmas X Kota Surabaya pada FebruariMaret 2017. Hasil penelitian menunjukkan pelaksanaan sistem rujukan di Puskesmas $X$ telah sesuai dengan peraturan dan pedoman yang ada. Pelaksanaan rujukan telah sesuai dengan 7 pasal Permenkes No.1 Tahun 2012 tentang Sistem Rujukan Perorangan. Pelaksanaan sistem rujukan telah sesuai dengan Pedoman Sistem Rujukan Nasional meliputi syarat merujuk pasien, prosedur klinis rujukan, dan prosedur administartif rujukan, namun terdapat pelaksanaan yang belum sesuai yakni pelaksanaan informed consent, menghubungi kembali faskes tujuan rujukan, dan lembar rujukan yang dicetak. Rekomendasi untuk puskesmas yaitu dengan membuat informed consent rujukan dan mencetak surat rujukan 2 rangkap.

Kata kunci: jaminan kesehatan nasional, puskesmas, sistem rujukan

\section{PENDAHULUAN}

Pusat Kesehatan Masyarakat (Puskesmas) sebagai salah satu jenis fasilitas pelayanan kesehatan tingkat pertama memiliki peranan penting dalam sistem kesehatan nasional, khususnya subsistem upaya kesehatan (Kemenkes RI, 2014). Puskesmas merupakan fasilitas pelayanan kesehatan yang menyelenggarakan upaya kesehatan masyarakat dan upaya kesehatan perseorangan tingkat pertama, dengan lebih mengutamakan upaya promotif dan preventif, untuk mencapai derajat kesehatan masyarakat yang setinggi-tingginya. Puskesmas perlu ditata ulang untuk meningkatkan aksesibilitas, keterjangkauan, dan kualitas pelayanan dalam rangka meningkatkan derajat masyarakat serta menyukseskan program jaminan sosial nasional.

Puskesmas merupakan pusat pelayanan kesehatan perorangan primer yang berfungsi sebagai gate keeper atau kontak pertama pelayanan kesehatan formal dan penakis rujukan sesuai standar pelayanan medis. Puskesmas harus dapat memberikan penanganan awal kasus medis yang masih dapat ditangani di puskesmas sebelum dilakukan rujukan kepada pasien (BPJS Kesehatan, 2014). Puskesmas memiliki peranan penting dalam 
penyelenggaraan Sistem Jaminan Kesehatan Nasional. Diberlakukannya program JKN membuat masyarakat yang akan berobat ke rumah sakit dengan kartu BPJS harus mendapat rujukan terlebih dahulu dari puskesmas (Zulhadi, et al., 2013). Rujukan ini diberikan kepada pasien BPJS jika puskesmas tidak dapat memberikan pelayanan kesehatan sesuai dengan kebutuhan pasien karena keterbatasan fasilitas, pelayan dan ketenagaan, serta diagnosis pasien diluar 155 diagnosis yang harus dilayani di puskesmas (BPJS Kesehatan, 2014). Sistem rujukan diselenggarakan dengan tujuan memberikan pelayanan kesehatan secara bermutu, sehingga tujuan pelayanan tercapai tanpa harus menggunakan biaya yang mahal (Putri, 2016). Sistem rujukan berjenjang merupakan salah satu upaya yang dilakukan dalam penguatan pelayanan primer, sebagai upaya untuk penyelenggaraan kendali mutu dan biaya. Peningkatan kerjasama fasilitas kesehatan merupakan salah satu strategi pengendalian mutu dan biaya pelayanan kesehatan (BPJS Kesehatan, 2016). Sistem rujukan berjenjang merupakan salah satu upaya peningkatan kerjasama antar fasilitas kesehatan. Sistem rujukan berjenjang merupakan salah satu upaya yang dilakukan dalam penguatan pelayanan primer, sebagai upaya untuk penyelenggaraan kendali mutu dan biaya pada Jaminan Kesehatan Nasional.

Peraturan Menteri Kesehatan Republik Indonesia Nomor 1 Tahun 2012 tentang Sistem Rujukan Pelayanan Kesehatan Perorangan menjelaskan bahwa sistem rujukan merupakan suatu penyelenggaran pelayanan kesehatan yang mengatur pelimpahan tugas dan tanggung jawab pelayanan kesehatan secara timbal balik baik vertikal maupun horizontal. Pelayanan kesehatan dilaksanakan secara berjenjang, sesuai kebutuhan medis dimulai dari pelayanan kesehatan tingkat pertama. Sistem rujukan diwajibkan bagi pasien yang merupakan peserta jaminan kesehatan atau asuransi kesehatan sosial dan pemberi pelayanan kesehatan (Kemenkes RI, 2012).

Sistem rujukan mengatur alur dari mana dan harus ke mana seseorang yang mempunyai masalah kesehatan tertentu untuk memeriksakan kesehatannya (Ali, et al., 2015). Sistem rujukan berarti bertujuan agar berjalan secara efektif sekaligus efisien yaitu berarti berkurangnya waktu tunggu dalam proses merujuk dan berkurangnya rujukan yang tidak perlu karena sebenarnya dapat ditangani di FKTP (Kemenkes RI, 2012). Era Jaminan Kesehatan Nasional memberlakukan sistem rujukan yang berjenjang, dimana pelayanan kesehatan dimulai di fasilitas kesehatan tingkat pertama (BPJS Kesehatan, 2014). Diberlakukannya sistem rujukan berjenjang mengharuskan pasien BPJS untuk mengutamakan berobat ke puskesmas yang merupakan fasilitas pelayanan primer. Jika pasien tidak dapat ditangani di fasilitas pelayanan primer baru diberlakukan rujukan pasien ke fasilitas pelayanan sekunder (ex: Rumah Sakit).

Peraturan BPJS Kesehatan tahun 2014 menjelaskan bahwa jumlah rujukan pasien di FKTP tidak boleh melebihi $15 \%$ dari total kunjungan pasien BPJS setiap bulannya. Puskesmas $X$ memiliki tingkat rujukan pasien yang tinggi, jumlah rujukan peserta JKN rata-rata sebesar 27\% tiap bulannya pada tahun 2016 sampai Maret 2017. Berdasarkan data rujukan pasien masih dijumpai pula beberapa pasien JKN yang diberikan rujukan atas permintaan pasien sendiri. Masih tingginya angka rujukan pasien menunjukkan bahwa puskesmas belum dapat melakukan pelayanan kesehatannya secara optimal sebagai gate keeper pelayanan kesehatan dalam masyarakat. Fungsi gate keeper puskesmas yaitu untuk mengkoordinir pelayanan kesehatan pada masyarakat dan untuk memaksimalkan efisiensi serta meningkatkan efektifitas pelayanan (Zuhrawardi, 2007).

Implementasi suatu sistem tidak akan berjalan baik jika pelaksanaannya tidak sesuai dengan ketentuan kebijakan atau pedomannya. Salah satu problem dalam implementasi sistem rujukan adalah keterbatasan sumber daya dan infrastuktur yang esensial dalam institusi kesehatan untuk menyediakan layanan kesehatan yang minimal (Luti, et al., 2012). Keterbatasan sumberdaya yang dimiliki puskesmas dan adanya berbagai permasalahan yang harus dihadapi oleh puskesmas, diperlukan keterpaduan dengan berbagai sektor untuk menunjang dan memaksimalkan pelaksanaan puskesmas salah satunya yaitu melakukan rujukan ke PPK lain untuk membantu menyelesaikan permasalahan yang dialami oleh masyarakat serta meningkatkan efisiensi (Chabibah \& Chalidyanto, 2014).

Tingginya angka rujukan menjadi indikasi bahwa sistem rujukan di Puskesmas $X$ belum terimplementasi dengan baik sehingga penting untuk melakukan kajian pelaksanaan sistem rujukan dengan membandingkan dengan pedoman sistem rujukan dari Peraturan Menteri Kesehatan Republik Indonesia Nomor 1 Tahun 2012 dan Pedoman Sistem Rujukan Nasional. Berdasarkan penjelasan diatas sehingga diperlukan penelitian untuk mengetahui kesesuaian pelaksanaan sistem rujukan di puskesmas dengan peraturan perundang-undangan yang berlaku. Manfaat penelitian yaitu untuk mendapatkan pengetahuan tentang pelaksanaan sistem rujukan pada era JKN di puskesmas sebagai bahan masukan pelaksanaan sistem rujukan pasien JKN di puskesmas, serta bahan evaluasi untuk perbaikan pelaksanaan sistem rujukan pasien JKN di puskesmas.

\section{METODE}

Jenis penelitian ini yaitu penelitian deskriptif observasional, dengan rancang bangun cross sectional. Metode dalam penelitian ini yaitu menggunakan riset implementasi. Penelitian ini melakukan triangulasi yang bertujuan untuk mendapatkan informasi mendalam dengan melakukan telaah terhadap dokumen rujukan pasien meliputi data rujukan, buku registrasi rujukan, rekam medis pasien, dan surat rujukan yang ada, wawancara dengan informan yaitu petugas rujukan Puskesmas $\mathrm{X}$, serta observasi secara langsung terhadap pelayanan pasien rujukan tanpa memberikan intervensi pada pelaksanaan sistem rujukan. Penelitian ini dilakukan di Puskesmas $X$ Kota Surabaya pada bulan Februari-Maret 2017. Informan dalam penelitian ini 
adalah dua orang Petugas Rujukan Puskesmas X Kota Surabaya yang berprofesi sebagai perawat. Pemilihan informan dilakukan dengan metode purposive sampling yaitu dengan mempertimbangkan keterlibatan petugas dengan pelaksanaan rujukan di puskesmas. Instrumen yang digunakan berupa panduan wawancara mendalam mengenai pelaksanaan sistem rujukan di Puskesmas $X$ yang disesuaikan dengan Permenkes No.1 Tahun 2012 dan Pedoman Sistem Rujukan Nasional. Analisis hasil yang digunakan dalam pelaksanaan sistem rujukan di Puskesmas X Kota Surabaya yaitu dengan membandingkan pelaksanaan sistem rujukan di lapangan dengan pedoman, kebijakan, dan atau peraturan yang berlaku.

\section{HASIL DAN PEMBAHASAN}

\section{Analisis Pelaksanaan Sistem Rujukan Peserta JKN di Puskesmas X Kota Surabaya menurut Peraturan Menteri Kesehatan Republik Indonesia Nomor 1 Tahun 2012 tentang Sistem Rujukan Pelayanan Kesehatan Perorangan}

Puskesmas merupakan fasilitas pelayanan kesehatan yang bekerja sebagai unit pelaksana teknis dinas kesehatan kabupaten atau kota yang bertanggung jawab menyelenggarakan pembangunan kesehatan di wilayah kerjanya. Permenkes No.1 Tahun 2012 menjelaskan bahwa fasilitas pelayanan kesehatan merupakan tempat yang digunkaan untuk menyelenggarakan upaya pelayanan kesehatan, baik promotif, preventif, kuratif maupun rehabilitatif yang dilakukan oleh pemerintah, pemerintah daerah, atau masyarakat. Puskesmas $X$ Kota Surabaya merupakan tipe puskesmas biasa atau puskesmas rawat jalan yang membuka pelayanan setiap hari senin-sabtu, dengan pelaksanaan pelayanan pagi dan sore dengan wilayah kerja meliputi $15 \mathrm{RW}$ dan $102 \mathrm{RT}$ dengan jumlah penduduk 48.528 jiwa pada tahun 2016. Pelayanan pagi dilakukan mulai pukul 07.3012.00 dan pelayanan sore dilakukan mulai pukul 15.00-17.30.

Sistem rujukan pelayanan kesehatan dilaksanakan secara berjenjang sesuai dengan kebutuhan medis (Goniwala, 2017). Sistem rujukan diselenggarakan dengan tujuan memberikan pelayanan kesehatan yang bermutu, sehingga tujuan pelayanan tercapai tanpa harus menggunakan biaya yang mahal (Ali, et al., 2015). World Health Organization (WHO) menjelaskan karakteristik rujukan medis adalah adanya kerja sama antara fasilitas pelayanan kesehatan, kepatuhan terhadap standar operasional prosedur (SOP) rujukan, kelengkapan sumberdaya pendukung termasuk transportasi dan komunikasi, kelengkapan formulir rujukan, komunikasi antar fasilitas kesehatan perujuk dan penerima rujukan serta pelaksanaan rujukan balik (Hartini, et al., 2016). Pelaksanaan rujukan harus memenuhi standar prosedur meliputi merujuk, menerima rujukan, membalas rujukan, menerima balasan rujukan, pengelolaan pasien di ambulans, dan rujukan kasus khusus (Gubernur Jawa Timur, 2016). Rujukan juga harus memenuhi persyaratan yaitu klinis dan administratif (Gubernur Jawa Timur, 2016).

Pelaksanaan sistem rujukan harus mengacu pada Peraturan Menteri Kesehatan Republik Indonesia Nomor 1 Tahun 2012 tentang Sistem Rujukan Pelayanan Kesehatan Perorangan. Pelaksanaan sistem rujukan harus disesuaikan dengan peraturan atau kebijakan agar berjalan secara efektif dan efisien. Pelaksanaan sistem rujukan di Puskesmas $X$ Kota Surabaya berdasarkan hasil implementasi di lapangan berupa observasi dan wawancara dijelaskan sebagai berikut:

Pelaksanaan rujukan dapat dilakukan secara vertikal dan horizontal (Pasal 7 ayat 1) dalam Permenkes No.1 Tahun 2012 dijelaskan bahwa Rujukan vertikal dari tingkat pelayanan yang lebih rendah ke tingkatan pelayanan yang lebih tinggi dapat dilakukan apabila pasien membutuhkan pelayanan spesialistik atau sub-spesialistik serta perujuk tidak dapat memberikan pelayanan kesehatan sesuai dengan kebutuhan pasien karena keterbatasan fasilitas, peralatan dan/atau ketenagaan kesehatan (Pasal 9) (Kemenkes RI, 2012). Pelaksanaan sistem rujukan vertikal, persetujuan pasien mengenai pemberian rujukan, serta format surat pengantar rujukan yang diberikan kepada pasien di Puskesmas X Kota Surabaya pelaksanaannya secara garis besar telah sesuai dengan ketentuan dalam peraturan perundangundangan tersebut. Berdasarkan wawancara yang dilakukan dengan pertugas rujukan dan observasi terhadap pelayanan secara langsung diketahui bahwa Puskesmas X Kota Surabaya melakukan rujukan kepada pasien yang membutuhkan pelayanan kesehatan spesialistik atau subspesialistik yang tidak dapat diberikan oleh puskesmas. Selain itu alasan keterbatasan fasilitas, peralatan dan/atau sumberdaya manusia atau ketenagaan, seperti tidak adanya dokter spesialis yang lebih berkompeten untuk menangani pasien dengan kasus yang membutuhkan pelayanan kesehatan spesialistik atau sub-spesialistik serta tidak terdapat beberapa pemeriksaan penunjang kebutuhan pelayanan kesehatan pasien yang dapat diberikan oleh rumah sakit kepada pasien yang membutuhkan rujukan di puskesmas.

Pelaksanaan rujukan yang terjadi di lapangan berbeda bahwa beberapa rujukan terjadi atas permintaan pasien, pasienpun menentukan dalam pemberian rujukan (Ali, et al., 2015). Namun tak jarang pula pada Puskesmas $\mathrm{X}$ terdapat pasien yang bersikeras untuk meminta dirujuk padahal kondisi kesehatannya tidak membutuhkan rujukan sehingga tak jarang dokter dan petugas rujukan berdebat dengan pasien yang meminta rujukan atas permintaan sendiri. Penelitian yang dilakukan Goniwala (2017) pasien menuntut jika menginginkan rujukan karena mereka kurang percaya dengan pelayanan kesehatan di faskes tingkat pertama, sehingga walaupun dijelaskan berulang-ulang bahwa penyakitnya dapat diobati di puskesmas namun bersikeras untuk tetap meminta rujukan dengan mengancam untuk keluar dari puskesmas.

Rujukan vertikal dari tingkatan pelayanan yang lebih tingi ke tingkatan pelayanan yang lebih 
rendah dapat dilakukan apabila permasalahan kesehatan pasien dapat ditangani oleh tingkatan pelayanan kesehatan yang lebih rendah sesuai dengan kompetensi dan kewenangannya, kompetensi dan kewenangan pelayanan tingkat pertama atau kedua lebih baik dalam menangani pasien tersebut, pasien membutuhkan pelayanan lanjutan yang dapat ditangani oleh tingkatan pelayanan kesehatan yang lebih rendah dan untuk alasan kemudahan, efisiensi dan pelayanan jangka panjang dan/atau perujuk tidak dapat memberikan pelayanan kesehatan sesuai dengan kebutuhan pasien karena keterbatasan sarana, prasarana, peralatan dan/atau ketenagaan (Pasal 10) (Kemenkes RI, 2012). Pelaksanaan rujukan vertikal dari tingkatan pelayanan yang lebih tinggi untuk kembali mendapatkan pelayanan di Puskesmas $X$ Kota Surabaya juga telah dilakukan sesuai dengan peraturan perundang-undangan. Berdasarkan hasil wawancara dengan petugas rujukan diketahui bahwa pasien rujuk balik dari fasilitas pelayanan kesehatan yang lebih tinggi untuk kembali berobat di puskesmas dilakukan apabila pasien dirasa oleh pihak dokter rumah sakit telah terkontrol kondisi kesehatannya, sehingga pengobatan pasien dikembalikan kepada pihak puskesmas.

Rujukan harus mendapatkan persetujuan dari pasien dan atau keluarganya, serta tenaga kesehatan yang berwenang harus memberikan penjelasan kepada pasien mengenai diagnosis dan terapi atau tindakan medis yang diperlukan oleh pasien, alasan dan tujuan dilakukan rujukan, risiko yang dapat timbul apabila rujukan tidak dilakukan, transportasi rujukan, dan risiko atau penyulit yang dapat timbul selama perjalanan (Pasal 12) (Kemenkes RI, 2012). Puskesmas X Kota Surabaya pun telah melakukan penjelasan kepada pasien atau keluarganya mengenai kondisi medis pasien, tindakan yang dibutuhkan, alasan dan tujuan dilakukan rujukan, serta risiko jika tidak dilakukan rujukan. Penjelasan mengenai transportasi rujukan dijelaskan secara umum mengenai transportasi umum yang kemungkinan dapat digunakan pasien untuk menuju tempat rujukan. Penjelasan oleh pihak puskesmas dilakukan dengan menggunakan bahasa yang sekiranya dapat dipahami oleh pasien atau keluarga pasien, biasanya menggunakan Bahasa Indonesia ataupun Bahasa Jawa.

Surat pengantar rujukan pasien sekurangkurangnya harus memuat mengenai identitas pasien, hasil pemeriksaan (anamnesis, pemeriksaan fisik dan pemeriksaan penunjang) yang telah dilakukan, diagnosis kerja, terapi/tindakan yang telah diberikan, tujuan rujukan, nama dan tanda tangan tenaga kesehatan yang memberikan pelayanan (Pasal 15) (Kemenkes RI, 2012). Surat pengantar rujukan yang diberikan oleh Puskesmas X Kota Surabaya telah sesuai dengan surat rujukan yang tersistem secara otomatis dalam Primary Care yaitu berupa surat rujukan resmi dari BPJS Kesehatan. Surat rujukan yang diberikan kepada pasien umum dibuatkan secara manual dan untuk pasien umum Surabaya Gratis yang tidak memiliki BPJS menggunakan form yang berasal Dinas Kesehatan Surabaya.

Berdasarkan penjelasan mengenai pelaksanaan sistem rujukan di Puskesmas X Kota Surabaya menurut Peraturan Menteri Kesehatan Republik Indonesia Nomor 1 Tahun 2012 tentang Sistem Rujukan Pelayanan Kesehatan Perorangan pada pasal 9-15 mengenai pelaksanaan rujukan vertikal dari pelayanan lebih rendah ke pelayanan lebih tinggi dan sebaliknya, serta mengenai persetujuan pasien dan surat rujukan telah sesuai dengan 7 pasal pada ketentuan yang diatur dalam Peraturan Menteri Kesehatan Republik Indonesia Nomor 1 Tahun 2012.

\section{Nasional}

Analisis Sistem Rujukan di Puskesmas X Kota Surabaya menurut Pedoman Sistem Rujukan Tabel 1 Analisis Sistem Rujukan di Puskesmas X Kota Surabaya menurut Pedoman Sistem Rujukan Nasional

\begin{tabular}{llcc}
\hline No & Pedoman Sistem Rujukan Nasional & $\begin{array}{c}\text { Pelaksanaan di Puskesmas X } \\
\text { Kota Surabaya }\end{array}$ & Telaah \\
\hline
\end{tabular}

Tata Laksana Rujukan dari Fasyankes Tingkat Pertama ke Tingkat Dua

\section{A. Syarat Merujuk Pasien}

1 Pasien yang akan dirujuk sudah diperiksa , dan disimpulkan bahwa kondisi pasien layak serta memenuhi syarat untuk dirujuk, tanda-tanda vital (vital sign) berada dalam kondisi baik/stabil serta transportable, dan memenuhi salah satu syarat untuk dirujuk.

\section{B. Prosedur Standar Merujuk Pasien}

1 Prosedur Klinis Rujukan:

1) Prosedur klinis pada kasus nonemergensi proses rujukan mengikuti prosedur rutin yang ditetapkan yaitu provider kesehatan menerima pasien di puskesmas, melakukan anamnesa, pemeriksaan fisik dan pemeriksaan penunjang medik yang mampu dilakukan puskesmas untuk menentukan diagnosa pada pasien

2) Pasien yang datang dalam keadaan emergensi dan membutuhkan pertolongan kedaruratan medik,

\section{Pelaksanaan rujukan di Puskesmas X Kota Surabaya telah memenuhi syarat merujuk pasien namun dalam beberapa kasus terdapat pasien yang tidak datang langsung puskesmas untuk mendapatkan rujukan.}

Pelaksanaan sistem rujukan di Puskesmas $\mathrm{X}$ Kota Surabaya dalam prosedur klinis telah mengikuti prosedur rutin yang telah ditetapkan namun belum memiliki SOP mengenai rujukan kasus non-emergensi. akan dirujuk, stabilisasi ini dilakukan pada 


\begin{tabular}{|c|c|c|c|c|}
\hline \multirow{2}{*}{\multicolumn{2}{|c|}{ No }} & \multirow{2}{*}{\multicolumn{2}{|c|}{\begin{tabular}{lllll} 
Pedoman Sistem Rujukan Nasional & & \multicolumn{3}{c}{$\begin{array}{c}\text { Pelaksanaan di Puskesmas X } \\
\text { Kota Surabaya }\end{array}$} \\
pertugas yang berwenang segera & pasien yang datang dalam keadaan \\
melakukan pertolongan & segera & emergensi dan diberikan pertolongan \\
(prosedur life saving) & untuk & kedaruratan pasien sesuai prosedur \\
menstabilkan kondisi pasien & sesuai & &
\end{tabular}}} & \multirow[t]{2}{*}{ Telaah } \\
\hline & & & & \\
\hline & 3) & $\begin{array}{l}\text { Menyimpulkan kasus bahwa pasien } \\
\text { memenuhi syarat untuk dirujuk, sesuai } \\
\text { dengan salah satu kriteria dalam syarat } \\
\text { merujuk pasien }\end{array}$ & $\begin{array}{l}\text { Puskesmas telah melaksanakan } \\
\text { penyimpulan kasus bahwa pasien memenuhi } \\
\text { syarat untuk dirujuk }\end{array}$ & Sesuai \\
\hline & 4) & $\begin{array}{l}\text { Mempersiapkan rujukan untuk pasien } \\
\text { dengan memberikan pasien dan atau } \\
\text { keluarganya penjelasan dengan } \\
\text { bahasa yang dimengerti } \\
\text { pasien/keluarga, dan informed consent } \\
\text { sebagai bagian dari prosedur } \\
\text { operasional yang sangat erat kaitannya } \\
\text { dengan prosedur teknis pelayanan } \\
\text { pasien harus dilakukan }\end{array}$ & $\begin{array}{l}\text { Puskesmas telah memberikan penjelasan } \\
\text { yang jelas kepada pasien/keluarga } \\
\text { mengenai rujukan yang akan diberikan } \\
\text { kepada pasien, namun tidak memberikan } \\
\text { lembar informed consent kepada pasien. }\end{array}$ & $\begin{array}{l}\text { Belum } \\
\text { Sesuai }\end{array}$ \\
\hline & 5) & $\begin{array}{l}\text { Penjelasan berkaitan dengan } \\
\text { penyakit/masalah kesehatan pasien } \\
\text { dan kondisi pasien saat ini, tujuan dan } \\
\text { pentingnya pasien harus dirujuk, } \\
\text { kemana pasien akan dirujuk, akibat } \\
\text { atau risiko yang terjadi apabila rujukan } \\
\text { tidak dilakukan, dan keuntungan } \\
\text { dilakukannya rujukan }\end{array}$ & $\begin{array}{l}\text { Setelah prosedur tindakan pra-rujukan } \\
\text { dilakukan untuk mempersiapkan rujukan } \\
\text { pihak medik puskesmas memberikan } \\
\text { penjelasan mengenai rujukan kepada } \\
\text { pasien/keluarga dengan bahasa yang mudah } \\
\text { dimengerti. }\end{array}$ & Sesuai \\
\hline & 6) & $\begin{array}{l}\text { Dilakukan rencana dan proses } \\
\text { pelaksanaan rujukan serta tindakan } \\
\text { yang mungkin akan dilakukan di faskes } \\
\text { rujukan yang akan dituju }\end{array}$ & $\begin{array}{l}\text { Puskesmas telah melakukan rencana dan } \\
\text { pelaksanaan rujukan serta tindakan yang } \\
\text { mungkin akan dilakukan di faskes rujukan } \\
\text { yang akan dituju kepada pasien yang akan } \\
\text { dirujuk }\end{array}$ & Sesuai \\
\hline & 7) & $\begin{array}{l}\text { Dijelaskan hal-hal yang perlu } \\
\text { dipersiapkan oleh pasien/keluarga, }\end{array}$ & $\begin{array}{l}\text { Puskesmas telah memberikan penjelasan } \\
\text { mengenai hal-hal yang perlu dipersiapkan } \\
\text { oleh pasien/keluarga }\end{array}$ & Sesuai \\
\hline & 8) & $\begin{array}{l}\text { Penjelasan-penjelasan lain yang } \\
\text { berhubungan dengan proses rujukan } \\
\text { termasuk berbagai persyaratan secara } \\
\text { lengkap untuk memberi kesempatan } \\
\text { pada pasien/keluarga }\end{array}$ & $\begin{array}{l}\text { Puskemas telah memberikan penjelasan lain } \\
\text { kepada pasien/keluarga sesuai yang } \\
\text { dibutuhkan. }\end{array}$ & Sesuai \\
\hline & 9) & $\begin{array}{l}\text { Putusan akhir rencana pelaksanaan } \\
\text { rujukan ada pada pasien dan atau } \\
\text { keluarganya untuk setuju atau menolak } \\
\text { untuk dirujuk sesuai alur rujukan yang } \\
\text { ada, serta kesepakatan akhir atau hasil } \\
\text { penjelasan dinyatakan dengan } \\
\text { pembubuhan tanda tangan dua belah } \\
\text { pihak dalam format informed consent } \\
\text { sesuai prosedur }\end{array}$ & $\begin{array}{l}\text { Pelaksanaan informed consent belum } \\
\text { dilakukan oleh pihak puskesmas, hanya } \\
\text { penjelasan kepada pasien atau keluarga } \\
\text { tanpa ada pembubuhan tanda tangan antara } \\
\text { dua belah pihak pasien/keluarga dengan } \\
\text { tenaga medis dalam format informed } \\
\text { consent sesuai prosedur. }\end{array}$ & $\begin{array}{l}\text { Belum } \\
\text { Sesuai }\end{array}$ \\
\hline & 10) & $\begin{array}{l}\text { Atas persetujuan rujukan dari } \\
\text { pasien/keluarga, puskesmas } \\
\text { berwenang mempersiapkan rujukan } \\
\text { dengan memberikan tindakan pra } \\
\text { rujukan sesuai kondisi pasien sebelum } \\
\text { dirujuk berdasarkan SPO }\end{array}$ & $\begin{array}{l}\text { Puskesmas telah meminta persetujuan dari } \\
\text { pasien/keluarga terlebih dahulu sebelum } \\
\text { mempersiapkan rujukan }\end{array}$ & Sesuai \\
\hline & 11) & $\begin{array}{l}\text { Puskesmas menghubungi kembali unit } \\
\text { pelayanan di faskes rujuan rujukan, } \\
\text { untuk memastikan sekali lagi bahwa } \\
\text { pasien dapat diterima di faskes rujukan } \\
\text { atau harus menunggu sementara } \\
\text { ataupun mencarikan faskes rujukan } \\
\text { lainnya sebagai alternatif }\end{array}$ & $\begin{array}{l}\text { Pihak puskesmas tidak menghubungi } \\
\text { kembali unit pelayanan faskes rujukan } \\
\text { apakah pasien dapat diterima di faskes } \\
\text { rujukan saat akan merujuk pasien. }\end{array}$ & $\begin{array}{l}\text { Belum } \\
\text { sesuai }\end{array}$ \\
\hline 2 & $\begin{array}{l}\text { Pro } \\
\text { 1) }\end{array}$ & $\begin{array}{l}\text { sedur Administratif Rujukan: } \\
\text { Dilakukan sejalan dengan prosedur } \\
\text { teknis pada pasien }\end{array}$ & $\begin{array}{l}\text { Pelaksanaan prosedur administratif } \\
\text { dilakukan sejalan dengan prosedur teknis } \\
\text { pada pasien }\end{array}$ & Sesuai \\
\hline
\end{tabular}




\begin{tabular}{|c|c|c|c|}
\hline No & Pedoman Sistem Rujukan Nasional & $\begin{array}{c}\text { Pelaksanaan di Puskesmas X } \\
\text { Kota Surabaya }\end{array}$ & Telaah \\
\hline 2) & $\begin{array}{l}\text { Melengkapi rekam medis pasien, } \\
\text { setelah tindakan untuk menstabilkan } \\
\text { kondisi pasien pra-rujukan }\end{array}$ & $\begin{array}{l}\text { Pihak puskesmas telah melengkapi rekam } \\
\text { medis pasien yang akan dirujuk serta } \\
\text { tindakan stabilisasi, kelengkapan berupa } \\
\text { diagnosis pasien, kode diagnosis, dan Poli } \\
\text { dan Rumah Sakit yang akan dituju untuk } \\
\text { rujukan }\end{array}$ & Sesuai \\
\hline 3) & $\begin{array}{l}\text { Setelah puskesmas memberikan } \\
\text { penjelasan secara lengkap dan } \\
\text { keputusan akhir telah diambil setuju } \\
\text { ataupun menolak untuk dirujuk, tetap } \\
\text { harus melengkapi informed consent } \\
\text { sesuai format prosedur untuk tanda } \\
\text { tangan kedua belah pihak, pihak } \\
\text { puskesmas dan pasien/keluarga }\end{array}$ & $\begin{array}{l}\text { Belum ada lembar informed consent yang } \\
\text { diberikan kepada pasien untuk tanda-tangan } \\
\text { persetujuan. }\end{array}$ & $\begin{array}{l}\text { Belum } \\
\text { Sesuai }\end{array}$ \\
\hline 4) & $\begin{array}{l}\text { Selanjutnya format informed consent } \\
\text { yang telah ditanda-tangani disimpan } \\
\text { dalam rekam medis pasien yang } \\
\text { bersangkutan, bila telah digunakan } \\
\text { perangkat TIK/ICT format informed } \\
\text { consent dapat dilengkapi dengan foto, } \\
\text { rekaman pembicaraan proses } \\
\text { pengambilan keputusan dan lainnya }\end{array}$ & $\begin{array}{l}\text { Belum ada lembar informed consent yang } \\
\text { diberikan kepada pasien untuk tanda-tangan } \\
\text { persetujuan, sehingga tidak ada informed } \\
\text { consent dalam rekam medis pasien yang } \\
\text { dirujuk. }\end{array}$ & $\begin{array}{l}\text { Belum } \\
\text { Sesuai }\end{array}$ \\
\hline 5) & $\begin{array}{l}\text { Selanjutnya apabila pasien sudah } \\
\text { setuju untuk dirujuk, maka puskesmas } \\
\text { harus membuat surat rujukan pasien } \\
\text { rangkap } 2 \text {, lembar pertama dikirim ke } \\
\text { faskes rujukan bersama pasien, lembar } \\
\text { kedua disimpan sebagai arsip bersama } \\
\text { rekam medis pasien yang akan dirujuk }\end{array}$ & $\begin{array}{l}\text { Puskesmas telah membuatkan surat rujukan } \\
\text { untuk pasien tetapi surat rujukan yang } \\
\text { dicetak hanya satu lembar yaitu untuk } \\
\text { diserahkan pada pasien, tidak ada lembar } \\
\text { rujukan kedua yang disimpan sebagai arsip } \\
\text { pada rekam medis yang dirujuk. }\end{array}$ & $\begin{array}{l}\text { Belum } \\
\text { Sesuai }\end{array}$ \\
\hline 6) & $\begin{array}{l}\text { Puskesmas harus mencatat pasien } \\
\text { pada buku register rujukan pasien }\end{array}$ & $\begin{array}{l}\text { Puskesmas telah mencatat rujukan pasien } \\
\text { pada buku register rujukan pasien yang diisi } \\
\text { secara rutin setiap hari }\end{array}$ & Sesuai \\
\hline 7) & $\begin{array}{l}\text { Administrasi pengiriman pasien harus } \\
\text { diselesaikan ketika pasien akan segera } \\
\text { dirujuk }\end{array}$ & $\begin{array}{l}\text { Administrasi } \\
\begin{array}{l}\text { pengiriman pasien } \\
\text { diselesaikan ketika pasien } \\
\text { dirujuk }\end{array}\end{array}$ & Sesuai \\
\hline
\end{tabular}

Prosedur rujukan diawali dari masyarakat yang membutuhkan pelayanan kesehatan dan harus dilakukan oleh tenaga kesehatan di FKTP dalam hal ini puskesmas (Gubernur Jawa Timur, 2016). Jika puskesmas tidak memiliki kemampuan dan kewenangan serta pasien membutuhkan pelayanan kesehatan lanjutan, puskesmas wajib merujuk. Prosedur rujukan yang dilakukan oleh puskesmas harus memenuhi standar prosedur meliputi: merujuk, menerima rujukan, membalas rujukan, menerima balasan rujukan, pengelolaan pasien di ambulans, dan rujukan kasus khusus (Gubernur Jawa Timur, 2016). Kelengkapan sarana dan prasarana di Puskesmas juga akan memperngaruhi dokter dalam memberikan rujukan kepada pasien (Zuhrawardi, 2007).

Tata laksana rujukan dari fasilitas pelayanan kesehatan tingkat pertama ke tingkat kedua terdiri dari syarat merujuk pasien dan prosedur standar merujuk pasien yaitu prosedur klinis dan administratif rujukan (Kemenkes RI, 2012). Pelaksanaan sistem rujukan di Puskesmas X Kota Surabaya menurut Pedoman Sistem Rujukan Nasional yang disusun oleh Kemenkes (2012) dapat diketahui sebagai berikut:

\section{Syarat Merujuk Pasien}

Syarat untuk merujuk pasien dalam Kemenkes RI (2012), yaitu:

1. hasil pemeriksaan sudah dapat dipastikan tidak mampu diatasi secara tuntas di fasyankes

2. hasil pemeriksaan fisik dengan pemeriksaan penunjang medis ternyata pasien tidak mampu diatasi secara tuntas ataupun tidak mampu dilayani karena keterbatasan kompetensi ataupun keterbatasan sarana/prasarana

3. pasien memerlukan pemeriksaan penunjang medis yang lebih lengkap dan pemeriksaan harus disertai pasien yang bersangkutan

4. apabila pasien telah diobati di puskesmas ternyata masih membutuhkan pemeriksaan, pengobatan dan atau perawatan di paskes rujukan yang lebih mampu untuk dapat menyelesaikan masalah kesehatan.

Pelaksanaan rujukan di Puskesmas X Kota Surabaya telah memenuhi syarat merujuk pasien sesuai Pedoman Sistem Rujukan Nasional. Penelitian yang dilakukan Zulhadi (2013), menjelaskan bahwa kesiapan puskesmas dan RSUD sebagai pusat rujukan belum sepenuhnya optimal, diantaranya keterbatasan sumber daya di pelayan dasar berupa fasilitas dan alat, walaupun tidak mempengaruhi sistem rujukan secara signifikan. Keterbatasan sumberdaya tersebut menyebabkan pemeriksaan yang dilakukan di 
puskesmas juga sangat terbatas sehingga akan mempengaruhi kebutuhan pasien untuk dirujuk.

Beberapa kasus di Puskesmas X terdapat pasien yang tidak datang langsung puskesmas untuk mendapatkan rujukan, sehingga hanya keluarga pasien yang menjelaskan kondisi medis pasien kepada tenaga medis puskesmas dan memintakan rujukan untuk pasien. Kondisi riil pasien yang tidak datang secara langsung ke puskesmas tidak bisa dipantau atau diperiksa terlebih dahulu oleh tenaga medis pihak puskesmas. Berdasarkan hasil wawancara dengan petugas rujukan Puskesmas $X$ Kota Surabaya mengenai pasien yang tidak datang langsung ke puskesmas, pihak puskesmas menanyakan terlebih dahulu kenapa pasien tidak datang dan meminta pasien datang sendiri jika alasan kondisi medis pasien masih memungkinkan untuk datang dan diperiksa dahulu di puskesmas, namun jika alasan bahwa pasien tidak datang sendiri ke puskesmas benar-benar karena kondisi medis pasien yang tidak memungkinkan untuk datang langsung ke puskesmas, maka pengecualian pihak puskesmas dapat memberikan rujukan. Namun dalam beberapa kasus seperti perpanjangan surat rujukan biasanya keluarga pasien yang memintakan surat rujukan ke puskesmas tanpa disertai pasien yang akan dirujuk karena alasan kondisi medis pasien.

\section{Prosedur Klinis Rujukan}

Pelaksanaan sistem rujukan di Puskesmas $\mathrm{X}$ Kota Surabaya dalam prosedur klinis telah sesuai dengan Pedoman Sistem Rujukan Nasional, prosedur telah mengikuti prosedur rutin yang telah ditetapkan. Berdasarkan penelitian yang dilakukan Ramah (2015) menyatakan bahwa mekanisme pelaksanaan sistem rujukan akan dilaksanakan melalui pemeriksaan awal oleh dokter puskesmas apaila pasien telah memenuhi salah satu kriteria pasien yang dapat dirujuk dan tidak dapat ditangani oleh puskesmas maka rujukan perlu dilakukan. Bila ditemukan kasus yang tidak dapat ditangani sesuai dengan kewenangan dokter, maka pasien tersebut segera dikirim ke unit pelayanan kesehatan yang memiliki kemampuan mengatasi masalah tersebut yaitu rumah sakit (Ramah, 2015).

Berdasarkan hasil observasi serta wawancara diketahui bahwa Puskesmas X Kota Surabaya belum memiliki SOP mengenai rujukan kasus non-emergensi. Berdasarkan hasil observasi langsung dalam pelayanan diketahui Puskesmas $X$ telah memiliki SOP mengenai stabilisasi kondisi pasien emergensi yang akan dirujuk, stabilisasi ini dilakukan pada pasien yang datang dalam keadaan emergensi dan diberikan pertolongan kedaruratan pasien sesuai prosedur. Berdasarkan hasil wawancara dengan petugas rujukan puskesmas telah melakukan penyimpulan kasus bahwa pasien memenuhi syarat untuk dirujuk. Persiapan pasien rujukan berdasarkan hasil observasi langsung dalam pelayanan diketahui bahwa puskesmas $\mathrm{X}$ telah memberikan penjelasan yang jelas kepada pasien/keluarga mengenai rujukan yang akan diberikan kepada pasien, namun tidak memberikan lembar informed consent kepada pasien.
Penjelasan mengenai rujukan berdasarkan hasil observasi dan wawancara dengan petugas rujukan di Puskesmas X Kota Surabaya, setelah prosedur tindakan pra-rujukan dilakukan untuk mempersiapkan rujukan pihak puskesmas memberikan penjelasan kepada pasien/keluarga dengan bahasa yang mudah dimengerti oleh pihak pasien bisa dalam bahasa indonesia ataupun bahasa jawa mengenai kondisi medis pasien, tujuan dirujuknya pasien, kemana pasien akan dirujuk biasanya pasien atau keluarga ditawari untuk memilih sendiri faskes lanjutan/rumah sakit yang ingin dituju sesuai dengan kemampuan aksesibilitas pasien untuk datang ke faskes rujukan.

Berdasarkan hasil wawancara dengan petugas rujukan serta observasi secara langsung diketahui bahwa puskesmas telah melakukan rencana dan pelaksanaan rujukan serta tindakan yang mungkin akan dilakukan di faskes rujukan yang akan dituju kepada pasien yang akan dirujuk, memberikan penjelasan mengenai hal-hal yang perlu dipersiapkan oleh pasien/keluarga, serta memberikan penjelasan lain kepada pasien/keluarga sesuai yang dibutuhkan.

Berdasarkan hasil wawancara dengan petugas rujukan dan observasi diketahui pelaksanaan informed consent belum dilakukan oleh pihak puskesmas, hanya penjelasan kepada pasien atau keluarga tanpa ada pembubuhan tanda tangan antara dua belah pihak pasien/keluarga dengan tenaga medis dalam format informed consent sesuai prosedur. Pelaksanaan di lapangan berdasarkan hasil wawancara yang dilakukan dengan petugas rujukan Puskesmas $X$ Kota Surabaya format lembar informed consent untuk pasien emergensi sudah ada namun untuk pasien non-emergensi belum ada, saat akan melakukan rujukan untuk kasus non-emergensi pasien/keluarga tidak diberikan lembar informed consent. Penelitian yang dilakukan Goniwala (2017) diketahui bahwa Puskesmas Tikala Baru dan Puskesmas Teling Kota Manado tidak ada informed consent untuk rujukan pasien, salah satu petugas mengatakan bahwa informed consent sangatlah penting terutama jika dilakukan tindakan terhadap pasien rujukan.

Pihak puskesmas belum menghubungi kembali unit pelayanan faskes tujuan rujukan apakah pasien dapat diterima di faskes tujuan rujukan saat akan merujuk pasien, berdasarkan hasil wawancara hal tersebut dikarenakan jumlah pasien yang dirujuk banyak sehingga tidak sempat jika harus menghubungi rumah sakit rujukan untuk setiap pasien yang akan dirujuk. Penelitian yang dilakukan Rukmini dan Ristrini (2015) diketahui bahwa Puskesmas Tambakrejo dan Tanah Kali Kedinding Surabaya sebelum melakukan rujukan persalinan menghubungi pihak RS tujuan terlebih dahulu, dan menyampaikan kasus yang akan dirujuk untuk menjamin tersedianya tempat di RS.

Rujukan yang efektif memerlukan komunikasi antar fasilitas, tujuannya agar pihak fasilitas terujuk mengetahui keadaan pasien dan dapat menyiapkan secara dini peannganan yang diperlukan pasien segera setelah pasien sampai di rumah sakit (Rukmini \& Ristrini, 2015). Namun untuk beberapa rumah sakit tertentu pihak 
puskesmas mendaftarkan secara online terlebih dahulu agar pasien mendapatkan nomor antrian tanpa perlu datang untuk mengambil nomor antrian. Sebelum era JKN tidak semua kasus yang akan dirujuk dikonfirmasikan terlebih dahulu ke RSUD namun pada era JKN dengan semakin ketatnya peraturan ketentuan indikasi rujukan maka komunikasi sebelum merujuk pasien terus diintensifkan untuk menjaga kesinambungan pelayanan sesuai dengan yang diharapkan dalam JKN (Primasari, 2015).

\section{Prosedur Administratif Rujukan}

Pelaksanaan prosedur administratif rujukan Puskesmas $X$ dilakukan sejalan dengan prosedur teknis pada pasien. Berdasarkan hasil observasi secara langsung pada Puskesmas $X$ diketahui pihak puskesmas telah melengkapi rekam medis pasien yang akan dirujuk serta tindakan stabilisasi, kelengkapan berupa diagnosis pasien, kode diagnosis, dan Poli dan Rumah Sakit yang akan dituju untuk rujukan. Berdasarkan hasil wawancara dan observasi diketahui bahwa belum ada lembar informed consent yang diberikan kepada pasien di
Puskesmas $X$ untuk tanda-tangan persetujuan, sehingga tidak ada informed consent dalam rekam medis pasien yang dirujuk. Format informed consent merupakan salah satu dokumen yang harus dimasukkan dalam pencatatan rekam medis pasien rujukan yang bersangkutan (Kemenkes RI, 2012).

Puskesmas telah membuatkan surat rujukan untuk pasien tetapi surat rujukan yang dicetak hanya satu lembar yaitu untuk diserahkan pada pasien untuk dibawa ke fakses tujuan rujukan, tidak ada lembar rujukan kedua yang disimpan sebagai arsip pada rekam medis yang dirujuk. Penelitian yang dilakukan Goniwala (2017) diketahui bahwa Puskesmas Tikala Baru dan Puskesmas Teling Kota Manado hanya mencetak satu lembar rujukan.

Pencatatan dan pelaporan sistem rujukan harus dilakukan dengan baik guna evaluasi terhadap berjalannya sistem rujukan (Primasari, 2015). Berdasarkan hasil observasi secara langsung diketahui puskesmas telah mencatat rujukan pasien pada buku register rujukan pasien yang diisi secara rutin setiap hari serta administrasi pengiriman pasien telah diselesaikan ketika pasien akan segera dirujuk.

Tabel 1 Pelaksanaan Sistem Rujukan yang Belum Sesuai dengan Pedoman Sistem Rujukan Nasional

\begin{tabular}{|c|c|c|c|}
\hline No & Kebijakan & Kenyataan Di Lapangan & Penyebab Ketidaksesuaian \\
\hline 1. & $\begin{array}{l}\text { Prosedur Standar Merujuk Pasien: } \\
\text { Prosedur Klinis Rujukan } \\
\text { Mempersiapkan rujukan untuk } \\
\text { pasien dengan memberikan pasien } \\
\text { dan atau keluarganya penjelasan } \\
\text { dengan bahasa yang dimengerti } \\
\text { pasien/keluarga, dan informed } \\
\text { consent sebagai bagian dari } \\
\text { prosedur operasional yang sangat } \\
\text { erat kaitannya dengan prosedur } \\
\text { teknis pelayanan pasien harus } \\
\text { dilakukan }\end{array}$ & $\begin{array}{l}\text { Puskesmas telah memberikan } \\
\text { penjelasan yang jelas kepada } \\
\text { pasien/keluarga mengenai } \\
\text { rujukan yang akan diberikan } \\
\text { kepada pasien, namun tidak } \\
\text { memberikan lembar informed } \\
\text { consent kepada pasien. }\end{array}$ & $\begin{array}{l}\text { Pihak puskesmas memberikan } \\
\text { informed consent kepada } \\
\text { pasien emergensi yang dirujuk } \\
\text { karena sudah terdapat prosedur } \\
\text { dalam SOP rujukan emergensi } \\
\text { dan puskesmas telah memiliki } \\
\text { format informed consent untuk } \\
\text { rujukan emergensi, namun } \\
\text { pasien non-emergensi belum } \\
\text { diberikan lembar informed }\end{array}$ \\
\hline 2. & $\begin{array}{l}\text { Putusan akhir rencana pelaksanaan } \\
\text { rujukan ada pada pasien dan atau } \\
\text { keluarganya untuk setuju atau } \\
\text { menolak untuk dirujuk sesuai alur }\end{array}$ & $\begin{array}{l}\text { Pelaksanaan informed consent } \\
\text { belum dilakukan oleh pihak } \\
\text { puskesmas, hanya penjelasan } \\
\text { kepada pasien atau keluarga }\end{array}$ & $\begin{array}{l}\text { consent dan puskesmas juga } \\
\text { belum memiliki format informed } \\
\text { consent untuk pasien non- } \\
\text { emergensi. }\end{array}$ \\
\hline
\end{tabular}
rujukan yang ada, serta tanpa ada pembubuhan tanda kesepakatan akhir atau hasil tangan antara dua belah pihak penjelasan dinyatakan dengan pasien/keluarga dengan tenaga pembubuhan tanda tangan dua medis dalam format informed belah pihak dalam format informed consent sesuai prosedur. consent sesuai prosedur

3. Puskesmas menghubungi kembali unit pelayanan di faskes rujuan rujukan, untuk memastikan sekali lagi bahwa pasien dapat diterima di faskes rujukan atau harus menunggu sementara ataupun mencarikan faskes rujukan lainnya sebagai alternatif

$\begin{array}{lrl}\text { Pihak puskesmas } & \text { tidak } & \text { Jumlah pasien yang berobat di } \\ \text { menghubungi kembali unit } & \text { puskesmas dan pasien yang } \\ \text { pelayanan faskes rujukan } & \text { dirujuk juga cukup banyak } \\ \text { apakah pasien dapat diterima di } & \text { sehingga pihak puskesmas } \\ \text { faskes rujukan saat akan } & \text { tidak sempat jika harus } \\ \text { merujuk pasien. } & & \text { menghubungi faskes lanjutan } \\ \text { untuk setiap pasien yang akan } \\ \text { dirujuk. Namun terdapat } \\ \text { beberapa Rumah Sakit yaitu } \\ \text { RS.Soewandhi dan RS. BDH, } \\ \text { pasien rujukan akan didaftarkan } \\ \text { online dahulu oleh pihak } \\ \text { puskesmas saat akan dirujuk } \\ \text { karena pihak rumah sakit tidak } \\ \text { menerima pasien jika faskes }\end{array}$




\begin{tabular}{|c|c|c|c|}
\hline No & Kebijakan & Kenyataan Di Lapangan & Penyebab Ketidaksesuaian \\
\hline & & & $\begin{array}{l}\text { perujuk tidak mendaftarkan } \\
\text { dahulu secara online pasien } \\
\text { yang akan dirujuk. }\end{array}$ \\
\hline 4. & $\begin{array}{l}\text { Prosedur Adminitratif Rujukan: } \\
\text { Setelah puskesmas memberikan } \\
\text { penjelasan secara lengkap dan } \\
\text { keputusan akhir telah diambil setuju } \\
\text { ataupun menolak untuk dirujuk, } \\
\text { tetap harus melengkapi informed } \\
\text { consent sesuai format prosedur } \\
\text { untuk tanda tangan kedua belah } \\
\text { pihak, pihak puskesmas dan } \\
\text { pasien/keluarga }\end{array}$ & $\begin{array}{l}\text { Belum ada lembar informed } \\
\text { consent yang diberikan kepada } \\
\text { pasien untuk tanda-tangan } \\
\text { persetujuan. }\end{array}$ & \multirow[t]{2}{*}{$\begin{array}{l}\text { Puskesmas X Kota Surabaya } \\
\text { telah memiliki format lembar } \\
\text { informed consent untuk pasien } \\
\text { rujukan emergensi, sedangkan } \\
\text { untuk pasien rujukan non- } \\
\text { emergensi belum memiliki } \\
\text { format untuk lembar informed } \\
\text { consent. Sehingga dalam } \\
\text { rekam medis tidak terdapat } \\
\text { arsip lembar informed consent. }\end{array}$} \\
\hline 5. & $\begin{array}{l}\text { Selanjutnya format informed consent } \\
\text { yang telah ditanda-tangani disimpan } \\
\text { dalam rekam medis pasien yang } \\
\text { bersangkutan, bila telah digunakan } \\
\text { perangkat TIK/ICT format informed } \\
\text { consent dapat dilengkapi dengan } \\
\text { foto, rekaman pembicaraan proses } \\
\text { pengambilan keputusan dan lainnya }\end{array}$ & $\begin{array}{l}\text { Belum ada lembar informed } \\
\text { consent yang diberikan kepada } \\
\text { pasien untuk tanda-tangan } \\
\text { persetujuan, sehingga tidak ada } \\
\text { informed consent dalam rekam } \\
\text { medis pasien yang dirujuk. }\end{array}$ & \\
\hline 6. & $\begin{array}{l}\text { Selanjutnya apabila pasien sudah } \\
\text { setuju untuk dirujuk, maka } \\
\text { puskesmas harus membuat surat } \\
\text { rujukan pasien rangkap 2, lembar } \\
\text { pertama dikirim ke faskes rujukan } \\
\text { bersama pasien, lembar kedua } \\
\text { disimpan sebagai arsip bersama } \\
\text { rekam medis pasien yang akan } \\
\text { dirujuk }\end{array}$ & $\begin{array}{l}\text { Puskesmas telah membuatkan } \\
\text { surat rujukan untuk pasien tetapi } \\
\text { surat rujukan yang dicetak hanya } \\
\text { satu lembar yaitu untuk } \\
\text { diserahkan pada pasien, tidak } \\
\text { ada lembar rujukan kedua yang } \\
\text { disimpan sebagai arsip pada } \\
\text { rekam medis yang dirujuk. }\end{array}$ & $\begin{array}{l}\text { Lembar rujukan tidak dicetak } \\
\text { rangkap } 2 \text { karena pemborosan } \\
\text { kertas. Data pasien yang dirujuk } \\
\text { telah dicatat/ditulis dalam rekam } \\
\text { medis pasien meliputi Kode } \\
\text { ICD-X, diagnosis, dan faskes } \\
\text { tujuan serta data telah diinput } \\
\text { dalam SIMPUS dan buku } \\
\text { register rujukan, serta dalam } P \text { - } \\
\text { Care untuk pasien BPJS. }\end{array}$ \\
\hline
\end{tabular}

Berdasarkan Tabel 1 pelaksanaan sistem rujukan pada Puskesmas $X$ yang belum sesuai disebabkan oleh beberapa hal untuk lembar informed consent yang belum diberikan disebabkan karena belum adanya format lembar informed consent untuk pasien rujukan non-emergensi. Puskesmas belum menghubungi kembali pihak faskes tujuan karena jumlah pasien rujukan yang terlalu banyak sehingga petugas tidak sempat jika harus menghubungi satupersatu pihak faskes tujuan. Tidak adanya lembar nformed consent dapat berdampak jika terjadi komplain atau masalah antara pihak pasien dengan puskesmas, informed consent dapat dijadikan bukti bahwa telah terjadi persetujuan sebelumnya untuk dilakukan rujukan.

Lembar rujukan tidak dicetak rangkap 2 namun pencatatan data pasien telah dilakukan pada rekam medis pasien yang meliputi data Kode ICD$X$, diagnosis, dan faskes tujuan serta data telah diinput dalam SIMPUS dan dicatat pada buku register rujukan, serta dalam $P$-Care untuk pasien JKN. Pencatatan tersebut telah dapat digunakan sebagai data pencatatan dan pelaporan pasien yang dirujuk. Namun jika terjadi kelalaian dalam pencatatan data rujukan pasien maka akan menyebabkan pencatatan dan pelaporan rujukan tidak valid dan kurang lengkap.

\section{SIMPULAN}

Analisis pelaksanaan sistem rujukan di Puskesmas X Kota Surabaya berdasarkan Peraturan Menteri Kesehatan Republik Indonesia Nomor 1 Tahun 2012 tentang Sistem Rujukan
Pelayanan Kesehatan Perorangan diperoleh hasil bahwa pelaksanaan sistem rujukan di Puskesmas $X$ Kota Surabaya pada pasal 9-15 mengenai pelaksanaan rujukan vertikal dari pelayanan lebih rendah ke pelayanan lebih tinggi dan sebaliknya, serta mengenai persetujuan pasien dan surat rujukan telah sesuai dengan 7 pasal dalam Permenkes No.1 Tahun 2012 tersebut.

Analisis pelaksanaan sistem rujukan di Puskesmas $X$ Kota Surabaya berdasarkan Pedoman Sistem Rujukan Nasional diperolah hasil bahwa syarat merujuk pasien di Puskesmas X Kota Surabaya telah memenuhi syarat merujuk pasien sesuai Pedoman Sistem Rujukan Nasional yaitu pada prosedur klinis dan prosedur administratif. Namun terdapat hal yang belum memenuhi syarat, dimana pasien yang diberi rujukan harusnya datang secara langsung di puskesmas untuk diperiksa dan diketahui kondisi medis pasien oleh dokter puskesmas sebelum dilakukan rujukan, namun hanya pihak keluarga pasien yang datang. Hal lain yang belum sesuai yaitu mengenai pemberian lembar informed consent, dan lembar rujukan. Saran yang perlu dilakukan Puskesmas $X$ yaitu dengan membuat lembar informed consent untuk pasien rujukan agar jika terdapat komplain atau masalah yang akan datang dapat dijadikan sebagai bukti bahwa telah terdapat persetujuan pasien atau keluarga pasien untuk dilakukan rujukan, serta meningkatkan komunikasi dengan faskes tujuan rujukan agar pelayanan rujukan pasien dapat diterima dengan baik tanpa ada penolakan serta akan terjalin hubungan yang efektif mengenai pertukaran informasi medis pasien. 


\section{DAFTAR PUSTAKA}

Ali, F. A., Kandou, G. \& Umboh, J., 2015. Analisis Pelaksanaan Rujukan Rawat Jalan Tingkat Pertama Peserta Program Jaminan Kesehatan Nasional (JKN) di Puskesmas Siko dan Puskesmas Kalumata Kota Ternate Tahun 2014. JIKMU, 5(2).

BPJS Kesehatan, 2014. Info BPJS Kesehatan: Ikuti Prosedurnya, Dapatkan Manfaatnya, Menggali Rujukan Berjenjang, s.l.: BPJS Kesehatan.

BPJS Kesehatan, 2014. Peraturan Badan Penyelenggaran Jaminan Sosial Kesehatan Nomor 1 Tahun 2014 Tentang Penyelenggaran Jaminan Kesehatan. s.I.:BPJS Kesehatan.

BPJS Kesehatan, 2016. Peraturan BPJS Nomor 8 Tahun 2016 Tentang Penerapan Kendali Mutu dan Kendali Biaya Pada Penyelenggaraan Program JKN. Jakarta: BPJS Kesehatan.

Chabibah, N. \& Chalidyanto, D., 2014. Analisis Rasio Rujukan Puskesmas Berdasarkan Kemampuan Pelayanan Puskesmas. Jurnal Administrasi Kesehatan Indonesia, 2(3).

Goniwala, G., 2017. Gambaran Pelaksanaan Rujukan Peserta BPJS Kesehatan di Puskesmas Tikala Baru dan Puskesmas Teling Atas di Kota Manado. [Online] Available at:

http://medkesfkm.unsrat.ac.id/wpcontent/uploads/2017/01/Geby-Goniwala1.pdf [Diakses 203 2017].

Gubernur Jawa Timur, 2016. Sistem Rujukan Kesehatan. Surabaya: s.n.

Hartini, Arso, . S. P. \& Sriatmi, A., 2016. Analisis Pelayanan Rujukan Pasien BPJS Di RSUD Chatib Quzwain Kabupaten Sarolangun Provinsi Jambi. Jurnal Kesehatan Masyarakat (e-Journal), 4(4).

Kemenkes RI, 2012. Pedoman Sistem Rujukan Nasional. Jakarta: Direktorat Jenderal Bina Upaya Kesehatan Kementerian Kesehatan $\mathrm{RI}$.

Kemenkes RI, 2012. Peraturan Menteri Kesehatan Republik Indonesia Nomor 01 Tahun 2012
Tentang Sistem Rujukan Pelayanan Kesehatan Perorangan. Jakarta: Kemenkes $\mathrm{RI}$.

Kemenkes RI, 2014. Peraturan Menteri Kesehatan Republik Indonesia Nomor 75 Tahun 2014 Tentang Pusat Kesehatan Masyarakat. Jakarta: Kemenkes RI.

Kemenkes RI, 2016. Peraturan Menteri Kesehatan Republik Indonesia Nomor 44 Tahun 2016 Tentang Pedoman Manajemen Puskesmas. Jakarta: Kemenkes RI.

Luti, I., Hasanbasri, M. \& Lazuardi, L., 2012. Kebijakan Pemerintah Daerah Dalam Meningkatkan Sistem Rujukan Kesehatan Daerah Kepulauan Di Kabupaten Lingga Provinsi Kepulauan Rlau. Jurnal Kebijakan Kesehatan Indonesia, 01(01), pp. 24-35.

Primasari, K. L., 2015. Analisis Sistem Rujukan Jaminan Kesehatan Nasional RSUD. Dr. Adjidarmo Kabupaten Lebak. Jurnal Administrasi Kebijakan Kesehatan, 1(2), pp. 78-86.

Putri, A., 2016. Tinjauan Pelaksanaan Sistem Rujukan Pasien BPJS Di Puskesmas Walantaka Kota Serang Banten, Jogjakarta: Universitas Gadjah Mada.

Ramah, P. A., 2015. Studi Tentang Pelayanan Publik Di Bidang Kesehatan Dengan Sistem Rujukan Di Puskesmas Air Putih Kecamatan Samarinda Ulu Kota Samarinda. eJournal IImu Pemerintahan, 3(1), pp. 81-94.

Rukmini \& Ristrini, 2015. Pelaksanaan Sistem Rujukan Maternal Di Puskesmas Tambakrejo dan Tanah Kali Kedinding Kota Surabaya. Buletin Penelitian Slstem Kesehatan, 18(4), pp. 365-375.

Zuhrawardi, 2007. Analisis Pelaksanaan Rujukan Rawat Jalan Tingkat Pertama Peserta Wajib PT.Askes Pada Puskesmas Mibo, Puskesmas Batoh dan Puskesmas Baiturahman Di Kota Banda Aceh Tahun 2017. Medan: Universitas Sumatera Utara.

Zulhadi, Trisnantoro, L. \& Zaenab, S. . N., 2013. Problematika Tantangan Puskesmas dan Rumah Sakit Umum Daerah Dalam Mendukung Sistem Rujukan Maternal di Kabupaten Karimun Provinsi Kepri Tahun 2012. Jurnal Kebijakan Kesehatan Indonesia, 2(04), pp. 189-201. 